\title{
Do vegetation patch spatial patterns disrupt the spatial organization of plant species?
}

\author{
C.L. Alados ,T. Navarro , B. Komac', V. Pascual , F. Martinez , B. Cabezudo , Y. Pueyo \\ Pyrenean Institute of Ecology (CSIC), Avda. Montañana 1005, P.O. Box 13034, 50192 Zaragoza, Spain \\ Department of Vegetal Biology, Málaga University, P.O. Box 59, 29080 Málaga, Spain \\ Department of Silvopasciculture, Botany Unit, E.T.S.J. de Montes, Madrid Polytechnic University, Ciudad Universitaria, 28040 Madrid, Spain \\ Department of Environmental Sciences, Copernicus Institute, Utrecht University, P.O. Box 80115, 3508 TC Utrecht, The Netherlands
}

Keywords:

Beta diversity

Detrended Fluctuation Analyses

Fractals

Fragmentation

Spatial patterns

\section{A B S T R A C T}

The mechanisms that structure plant diversity and generate long-range correlated spatial patterns have important implications for the conservation of fragmented landscapes. The ability to disperse and persist influences a plant species' capacity for spatial organization, which can play a critical role in structuring plant diversity in metacommunities. This study examined the spatial pattems of species diversity within a network of patches in Cabo de Gata Natural Park, southeastern Spain. The objectives were to understand how the spatial heterogeneity of species composition (beta diversity) varies in a structured landscape, and how the long-range spatial autocorrelation of plant species is affected by the spatial configuration of patches.

The mechanisms underlying the spatial distribution of plants acted at two scales. Between patches, spatial variation in species distributions was greater than that expected based on spatial randomization, which indicated that movement among patches was restricted. Within patches, diffusion processes reduced spatial variability in species distributions, and the effect was more prominent in large patches. Small patch size negatively influenced the long-range spatial autocorrelation of characteristic species, whereas interpatch distance had a stronger effect on species frequency than it had on the disruption of spatial organized patterns.

The long-range spatial autocorrelation was evaluated based on the dispersal abilities of the species. Among the 106 species evaluated, $39 \%$ of the woody species, $17 \%$ of the forbs, and $12 \%$ of the grasses exhibited disrupted long-range spatial autocorrelation where patches were small. The species that are more vulnerable to the effects of fragmentation tended to be those that have restricted dispersal, such as those that have short-range dispersal (atelechoric), e.g., Phlomis purpurea, Cistus abidus, Teucrium pseudochamaepytis, Brachypodium retusum, and the ballistic species, Genista spartioides. Helianthemum aimeriense is another vulnerable species that has actively restricted dispersal (antitelechory), which is common in arid regions. Wind dispersers such as Launaea lanifera were less vulnerable to the effects of fragmentation. Long-distance dispersers whose persistence depends on facilitative interactions with other individuals, e.g., allogamous species such as Thymus hyemalis, Ballota hirsuta, and Anthyllis cytisoides, exhibit disrupted long-range spatial autocorrelation when patch size is reduced. 


\section{Introduction}

With an increasing rate of habitat loss and fragmentation (Thomas et al., 2004) and its deleterious effects on population persistence (Fisher and Stöcklin, 1997; Hanski, 1999) and biodiversity (Tilman, 1994; Solé et al, 2004), conservation ecologists are faced with the task of understanding the relative importance of the underlying mechanisms that determine species diversity at multiple scales. The additive partitioning of species diversity is a way to quantify the components of diversity among scales and measure the contribution of local communities to regional diversity (Lande, 1996; Wagner et al., 2000; Crist et al., 2003; Gering et al., 2003; Freestone and Inouye, 2006). The partitioning of plant species diversity across landscapes and regions has been investigated in agricultural landscapes (Wagner, 2003; Gabriel et al., 2006) and serpentine outcrops (Davies et al., 2005; Freestone and Inouye, 2006), but limited attention has been paid to the role of self-organizing capacity as a mechanism underlying the spatial structure of communities (Alados et al., 2005; Green and Sadedin, 2005; Seabloom et al., 2005; Barbier et al., 2006). Spatial self-organization is the ability of a non-equilibrium system to develop structure and pattern in the absence of control by external agents (Nicolis, 1989). Sound conservation strategies depend on a thorough understanding of the self-organizing capacity of ecosystems.

Vegetation spatial pattems can be generated in strictly isotropic environments (Lefever and Lejeune, 1997; Lejeune et al., 2002; Barbier et al., 2006) and can result from the selforganizing capacity through plant interactions and dispersal (Bolker and Pacala, 1999; Green and Sadedin, 2005; Seabloom et al., 2005). Plant life-history traits such as dispersal capacity, clonal spreading, and plant pollination can affect vegetation spatial patterns through their influence on plant recruitment and establishment, and by neighborhood effects (Frelich et al., 1998; Schwarz et al., 2003). For example, in species that have limited dispersal capacity, spatial autocorrelation is high (Miller et al., 2002). In addition, during the early stages of colonization, random distributions arise (Kershaw, 1963; Fowler, 1990; Solé and Bascompte, 2006). Above a threshold in abundance, the probability of interactions increases, which triggers the positive feedback mechanisms that underlie plant facilitation (Bertness and Callaway, 1994; Pugnaire et al., 1996; HilleRisLambers et al., 2001) and the system moves toward a more clumped spatial organization (Aarssen and Turkington, 1985; Loehle et al., 1996; Soro et al., 1999; Solé and Bascompte, 2006). Those nonlinear interactions involve amplifications that operate through feedback loops (Jensen, 1998). As ecosystems develop, long-range spatial autocorrelations arise, which lead the systems toward an increase in the heterogeneity of species distributions (Loehle et al., 1996). In contrast, an increase in disturbance often leads to unpredictability (randomness) in species distributions (Alados et al., 2003, 2005; Seabloom et al, 2005).

In this study, we assessed the effect of vegetation patch spatial patterns on the spatial distribution of diversity, disruption of the long-range autocorrelations of species, and the importance of plant dispersal, plant pollination, and persistence capabilities. In the short term, spatial patchiness can increase opportunities for species recruitment (Fahrig, 2003; Hobbs and Yates, 2003; Harper et al., 2005), which alters successional states and environmental conditions. In the long term, however, fragmentation can disrupt mutualistic interactions (Jennersten, 1988). Dispersal potential influences competitive coexistence and responses to fragmentation (Chesson and Huntly, 2000; Fahrig, 2003; Davies et al., 2005), which might result in an invasion by a fast colonizer, which counterbalances the poorly colonizing species that are lost through fragmentation. For example, dominant species strongly influence the biotic conditions experienced by other species and are important forces in ecosystem functioning and community dynamics (Grime, 1998; Wright, 2008). A change of dominant species can alter the facilitative-competitive relationship among other species in the community. A shift in the dominance hierarchy can change community structure and dynamics, which can have important effects on the biodiversity of ecosystems (Klanderud and Totland, 2005). Thus, changes in the biotic components of ecosystems can have more significant effects than those that are apparent, initially, because of a cascade of factors that act on interacting species (Solé et al, 2004)

To distinguish exogenous heterogeneity (spatial variability caused by environmental conditions) from endogenous heterogeneity (spatial variability caused by intrinsic components), we used Detrended Fluctuation Analysis (DFA). DFA (Peng et al., 1992; Peng et al., 1994) is used extensively for the detection of long-range autocorrelations in non-stationary data series, e.g., DNA (Buldyrev et al., 1995), heart rate (Ashkenazy et al., 2001; Ivanov et al., 2002), climate dynamics (Kantelhardt et al., 2001), behavior timeseries (Alados and Weber, 1999), and vegetation spatial patterns (Alados et al., 2003; Telesca and Lasaponara, 2006; Telesca et al., 2008).

This study addressed the following questions:

(1) Do patch spatial patterns (patch size and inter-patch distance) influence the spatial distribution of plant diversity?

(2) Is the long-range spatial autocorrelation of plant species affected by patch spatial patterns?

(3) Does the long-range spatial autocorrelation of plants in patchy landscapes depend on life-history traits (dispersal, pollination, and persistence)?

\section{Methods}

\subsection{Study area}

The study occurred in Cabo de Gata Natural Park (37,570 ha), southeastem Spain. Elevation ranges from sea level to $493 \mathrm{~m}$ at El Fraile Peak, and the climate is Mediterranean semi-arid. At $43 \mathrm{~m}$ a.s.l, between 1973 and 1996, average annual rainfall was $193.9 \mathrm{~mm}$ and mean annual temperature was $19.4^{\circ} \mathrm{C}$. The ecological community of the volcanic portion of the park is dominated by a dense dwarf matorral of Chamaerops humilis, along with Rhamnus lycioides, Pistacia lentiscus, and Periploca laevigata (Peinado et al., 1992). Historically, the area was 
exploited mainly by traditional agro-pastoral systems, with cereal cultivation on the floodplains and livestock (sheep and goats) grazing on the slopes. In 1804-1809, Simón de Rojas (Gil Albarracín, 2002) described a vegetation community that was similar to what existed in 2007 , where limited rainfall and a scarcity of aquifers limited the presence of humans. Those conditions have favored the preservation of plant communities in the Cabo de Gata Natural Park. We selected 14 sites that encompassed all of the vegetation patches in the core area of the volcanic part of the park. Patches were on the hills, which were separated by agnicultural lands in the valleys.

\subsection{Data collection and analysis}

In April 2006, we surveyed the vegetation in the 14 patches, which were between 2.9 ha and 3349.5 ha in size. Within each patch, at least three $500-\mathrm{m}$ linear transects (52 transects in total) were established. To estimate plant abundance and richness within each transect, we used the Point-Intercept method, which involves recording the identity of all individuals in contact with a vertical nail at $20-\mathrm{cm}$ intervals (Gooda]l, 1952). That method assumes isotropy; therefore, to avoid anisotropy, transects were positioned oblique to the slope and along different randomly selected angles.

To quantify patch sizes, digitized vegetation maps that were derived from orthorectified aerial photographs taken in 1994 were subjected to GIS (Geographic Information System) analyses (Alados et al., 2004). Inter-patch distances were calculated based on $\sum_{j} D_{i j}$. $D_{i j}$ is the distance from patch-edge $i$ to patch-edge $j$. To calculate the distances between the edges of patches (assumed to be circles), patch radii were subtracted from the Euclidean center-to-center distances (Moilanen, 2004).

For each transect, the Shannon index $\left(H^{\prime}\right)$ and the Information Fractal Dimension $\left(D_{\mathrm{I}}\right)$ was calculated. $D_{\mathrm{I}}$ quantifies vegetation homogeneity ( $\mathrm{Li}, 2000$; Chen et al., 2005). The larger the $D_{\mathrm{I}}$ the more homogeneous is the distribution of plant species. We calculated the Information Fractal Dimension, $D_{I}$, at a series of scales of size $\varepsilon=2^{n}$, for $n$ from 0 to 6 , i.e., $1,2,4 \ldots$ $64 \mathrm{~m}$, where $\mathrm{D}_{1} \cong \lim _{\varepsilon-0} H_{\{\varepsilon}^{\prime} /(\ln 1 / \varepsilon)$ (Farmer et al., 1983). $\mathrm{H}_{\{\varepsilon)}^{\prime}$ changes with window size $(\varepsilon), H_{i \varepsilon j}^{\prime}=\sum_{i=1}^{N_{(i)}} p_{i} \ln \left(1 / p_{i}\right)$, where $p_{i}$ is the proportion of intercepts attributed to plant species $i$, which depends on the length of the transect segment (window size $=\varepsilon$ ) over which presence or absence is recorded. The $D_{1}$ values were constrained between 0 and 1 because onedimensional linear transects provided the fractal dimension. To determine whether patch spatial patterns influenced plant species distributions, we evaluated the effects of patch size and inter-patch distance on $D_{\mathrm{I}}$, species richness, species diversity $\left(H^{\prime}\right)$, and proportion of bare soil.

Beta, $\beta$, diversity is the variation in species composition among sites within a region (Whittaker, 1960, 1972). Gamma, $\gamma$, diversity is the overall species diversity found in a collection of samples, and it is partitioned in to the average diversity within samples $(\alpha)$ and among samples $(\beta)$, i.e., $\gamma=\alpha+\beta$ (Wagner et al., 2000 ). In a nested hierarchical design, $\alpha_{i}$ is the average diversity within samples at level $i$, and $\beta_{i}=\alpha_{i+1}-\alpha_{i}$ (Allan, 1975; Lande, 1996; Wagner et al., 2000; Crist et al., 2003; Gering et al., 2003). In this study, we used a hierarchical design with $i=1,2$, and 3 nested levels, where level 1 was transect, level 2 was patch, and level 3 was the region under study. Sampling effort can influence estimates of species richness; therefore, to avoid bias in the comparisons of the diversity of sites, we used three transects per patch.

To determine the extent to which spatial patterns of diversity were influenced by scale, we compared the observed diversity partitions and the null hypothesis of random spatial differentiation of diversity among samples at multiple scales. To test for nonrandom $\beta$ diversity, we performed a standard randomization routine (Manly, 2007). Randomization was performed using the same frequency distribution of each species and distribution of sampling effort as observed in the original data (Freestone and Inouye, 2006). To run the randomization models at two levels (following Crist et al. (2003), we used Matlab 7.01. In the sample-based randomization, samples were randomized at each hierarchical level and, in the individual-based randomization, randomization occurred at the individual level, only, and each randomized data set was partitioned into $\alpha$ and $\beta$ components at each hierarchical level. If individual aggregation significantly influences diversity partitioning, $\beta$ will be higher than expected based on a random distribution. Individual-based randomization is useful for assessing the importance of individual aggregation on the diversity partitioning, while sample-based randomization emphasizes the extent to which different patches are contributing to the regional diversity. In addition, we evaluated the influence of patch size and patch distance on among-transect beta diversity $\left(\beta_{1}\right)$.

To assess the self-organized spatial patterns of each species, we used Detrended Fluctuation Analysis to quantify the degree of spatial clustering of each species' cover, independent of the scale of measurement DFA can detect long-range autocorrelations in fluctuations that are embedded in an apparently non-stationary sequence (Peng et al., 1994; Alados and Weber, 1999; Hu et al., 2001). DFA can remove trends influenced by external factors, e.g., soil structure, from endogenous fluctuations. DFA is a better method for quantify the scaling behavior of noisy signals than is classical analysis (Taqqu et al., 1995; Hu et al., 2001). In the DFA, the integrated sequence $y(s)=\sum_{i}^{s} x(i)$ was subdivided into non-overlapping sequential sets or 'boxes' of size $b(x(i)=+1$ for presence, and $x(i)=-1$ for absence). The long-range spatial correlation of individual species was evaluated based on the presence (+1) and absence ( -1$)$ of each species, separately. A regression line was fit to each box of size $b$; i.e., $y_{b}(s)$ was regressed on $s$, and the residual variance per each box size was calculated from $F^{2}(b)=\sum\left(y_{b}(s)-\hat{y}_{b}(s)\right)^{2} / N$. To provide the scale of the relationship $F_{(b)} \propto b^{\circ}$, that process was repeated for scales $4,6,8 \ldots$ 512 points along the first 2050 points of each transect. Following Halley et al. (2004), we chose a minimum scale that was greater than the minimum species crown diameter (interpoint separation), and a maximum inter-point distance (coarse resolution) of one quarter of the transect. To allow long-range autocorrelations and to prevent superposing trends from the land topography, long sequences (2050 points, i.e., 500-m transects) were used. The $\rho$ parameter reflects the long-range autocorrelations of the plant distribution sequences. It is equivalent to the Hurst Exponent (Hausdorff et al., 1997), but it is a superior method for quantifying longrange correlations (Hu et al., 2001; Livina and Lenton, 2007). 
Theoretically, $\rho$ is unaffected by the magnitude of the fluctuations in the sequences, but affected by the sequential ordering of the fluctuations. If $\rho>1 / 2$, the sequence depends on the history of the distribution and, when $\rho=1 / 2$, the sequence is randomly distributed. To detect disruptions in long-standing, self-organized processes, we evaluated the correlations between the $\rho$ exponent of each plant species in each patch and patch size and inter-patch distance.

All of the nonlinear adjustments were performed using the Gauss-Newton Method (SAS Institute, 2004). When X and $Y$ were subject to error, we performed orthogonal regressions. Except where noted otherwise, values are presented as mean \pm standard error. We performed statistical analyses using SAS 9.1.

\section{Results}

\subsection{Influence of patch size and isolation on the additive} partitions of beta diversity

At 14 sites in Cabo de Gata N.P., in southeastern Spain, vegetation patches did not differ significantly in the extent of disturbance. The proportion of bare soil $\left(F_{1,51}=0.22\right.$, NS), species richness $\left(F_{1,51}=0.68, N S\right)$, and species diversity $\left(F_{1,51}=2.12\right.$, NS $)$ were not correlated with patch size, which suggests that there was no relationship between habitat degradation and patch size.

The additive partitions of the Shannon diversity showed that $\alpha_{1}$ diversity explained $77 \%$ of the vascular plant diversity of Cabo de Gata N.P., and 5\% could be attributed to amongtransect variation $\left(\beta_{1}\right)$. Among-patch variation $\left(\beta_{2}\right)$ explained $17 \%$ of the overall variance (Fig. 1). The levels of $\beta_{1}$ diversity were significantly lower than expected based on the individual- and sample-based randomizations $(t=-3.517, P<0.05$, $t=-3.155, P<0.001$, respectively). In contrast, among-patch diversity $\left(\beta_{2}\right)$ was significantly higher than expected based on the individual-based randomization $(t=2.045, P<0.05)$. The observed $\beta_{2}$ did not differ significantly $(t=0.606$, NS) from the expected based on the sample-based randomization because the among-sample randomization maintained species aggregations in the randomization of the sample units (Table 1).

The relationship between beta diversity $\left(\beta_{1}\right)$ and patch size fit significantly $\left(F_{1,11}=16.90, P<0.001\right)$ a negative exponential curve (Fig. 2). The larger the patch size, the lower the among-

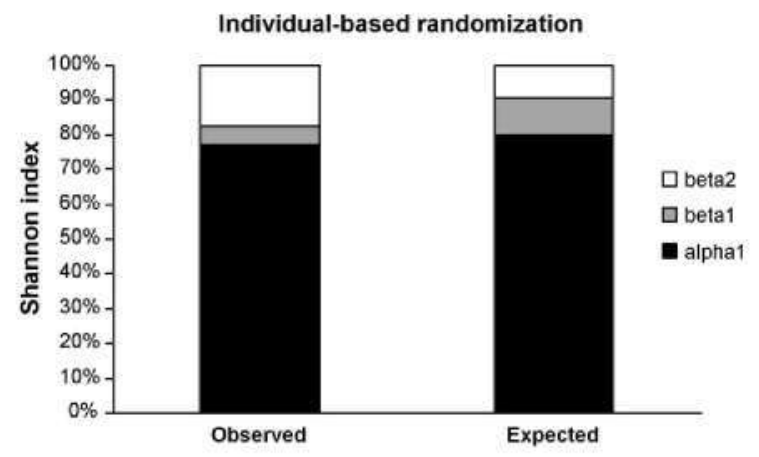

Fig. 1 - Contributions of the additive partitions of the overall Shannon Diversity explained by each hierarchical level in the dwarf matorral community in Cabo de Gata Natural Park, SE Spain. The observed partitions were compared to the values expected from individual-based randomizations. Alpha $1\left(\alpha_{1}\right)$ is within-transect diversity, beta $1\left(\beta_{1}\right)$ is among-transect diversity, beta $2\left(\beta_{2}\right)$ is among-patch diversity.

transect variation. Inter-patch distance and $\beta_{1}$ diversity were not correlated $\left(F_{1,11}=0.01\right.$, NS).

\subsection{Influence of patch size and isolation on the spatial organization of plant species}

Of the 240 species documented in our study, 106 (31 woody species, 58 forbs, and 17 grasses) occurred in more than four transects and, therefore, were included in the analysis. Overall, $39 \%$ of the woody species, $17 \%$ of the forbs, and $12 \%$ of grasses exhibited a significant increase in long-range spatial autocorrelation (DFA) with an increase in patch size. In $6 \%$ of the woody species, and $7 \%$ of the forbs, DFA was negatively correlated with patch size, and these are species adapted to arid and degraded soils. Thirty-six species provided $84 \%$ of the plant cover (Table 2). In general, long-lived species and large shrubs had higher DFA values than did herbs, which distributed themselves more opportunistically. All of the DFA values were significantly $>0.5$, which indicated that the species were not randomly distributed. Linear regressions between the DFA values of the most abundant species and patch size (Table 3 ) indicated that small patch size had a

Table 1 - Observed and expected alpha-, beta-, and gamma-diversity derived from a randomization model. In parenthesis are the $95 \%$ confidence limits from individual- and sample-based randomization). The standard randomization routine was performed on individual-based and sample-based randomizations.

Observed

Individual-based randomization

Expected

\begin{tabular}{lll}
\hline$\alpha_{1}$ & 2.571 & $2.657(2.676,2.639)$ \\
$\alpha_{2}$ & 2.747 & $3.009(3.022,2.996)$ \\
$\alpha_{3}$ & 3.322 & \\
$\beta_{1}$ & 0.175 & $0.352(0.345,0.361)$ \\
$\beta_{2}$ & 0.575 & $0.312(0.300,0.325)$ \\
$\gamma$ & 3.322 & 3.322
\end{tabular}

Sample-based randomization

$2.657(2.676,2.639)$

$2.825(2.844,2.805)$

$0.338(0.333,0.344)$

$0.497(0.478,0.516)$

3.322 


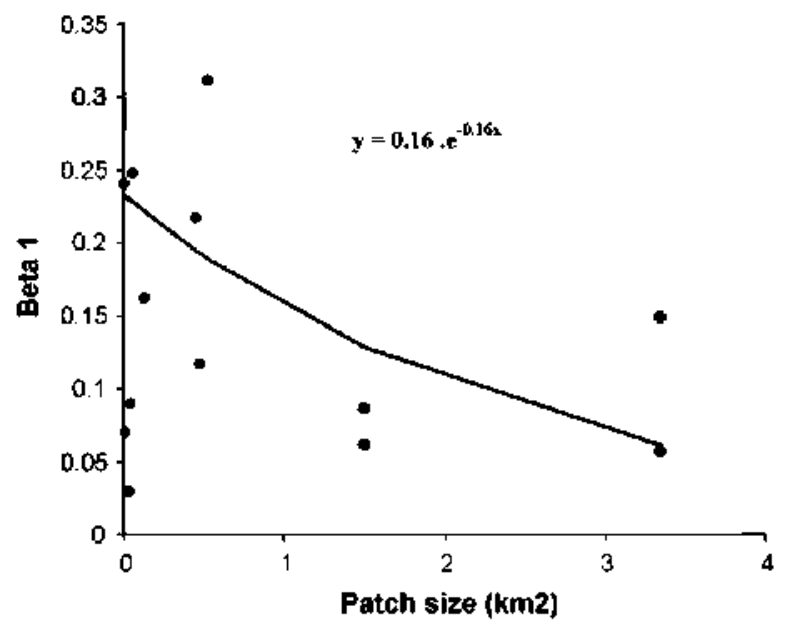

Fig. 2 - Non-linear adjustments based on the GaussNewton method for changes in beta $1\left(\beta_{1}\right)$ diversity and patch size ( $\mathrm{km})$ of the dwarf matorral community in Cabo de Gata Natural Park, SE Spain. negative effect on the large evergreen sclerophyllous shrubs, e.g., the xeric thomy-shrub Periploca laevigata and the dwarfpalm Chamaerops humilis, which are the climax species in Cabo de Gata N.P., the xeric shrubs that characterize the low, open matorral, e.g., Thymus hyemalis, Helianthemum almeriense, Ballota hirsuta, and Teucrium pseudochamaepytis, the glaucous dwarf-shrubs in successional xeric stages, e.g., Phlomis purpurea and Cistus albidus, the large shrub legumes Genista spartioides and Anthyllis cytisoides, the short-grasses associated with the low, open matorral, e.g., Brachypodium retusum and Bromus rubens, and the annual Linum strictum (Fig. 3). In some species, such as the xeric prostrate herbs Fagonia cretica and Phagnalon saxatile, which are adapted to very dry environments, small patch size increased DFA, and these species have an advantage when habitat fragmentation increases (Fig. 4).

Most of the species that exhibited a reduction in DFA also declined in frequency with a decrease in patch size, but the effect was not universal because factors other than fragmentation influence species frequency. For example, $P$. laevigat $a$ is influenced by proximity to the sea, and was absent in inland patches. The frequency of some species, e.g., L. multifida, A. horridus, and S. genistoides, decreased with a decrease in patch

Table 2 - Coverage (\%) and DFA exponents, $p$, of the most abundant plant species in the dwarf matorral of Cabo de Gata Natural Park, SE Spain, t-Tests were used to compare the DFA and the random distribution (DFA $=0.5)$. All of the tests were significant at $P<0.001$.

\begin{tabular}{|c|c|c|c|}
\hline Species & Cover $(\%)$ & DFA mean \pm S.E. (n) & $\mathrm{t}$ \\
\hline Stipa tenacissima & 34.84 & $0.833 \pm 0.011(52)$ & 31.39 \\
\hline Chamaerops humilis & 6.91 & $0.875 \pm 0.009(50)$ & 42.59 \\
\hline Brachypodium retusum & 4.89 & $0.781 \pm 0.014$ & 19.49 \\
\hline Thymus hyemalis & 4.73 & $0.664 \pm 0.009(53)$ & 19.05 \\
\hline Periploca íaevigata & 3.80 & $0.770 \pm 0.014(38)$ & 19.60 \\
\hline Brachypodium distachyon & 2.41 & $0.677 \pm 0.015(39)$ & 11.59 \\
\hline Plantago amplexicaulis & 2.34 & $0.680 \pm 0.010$ & 18.37 \\
\hline Phlomis purpurea & 1.81 & $0.715 \pm 0.010(45)$ & 21.49 \\
\hline Launaea lanifera & 1.78 & $0.683 \pm 0.009(48)$ & 19.72 \\
\hline Anthyllis cytisoides & 1.35 & $0.722 \pm 0.018(17)$ & 12.25 \\
\hline Asparagus horridus & 1.24 & $0.581 \pm 0.011$ & 7.34 \\
\hline Stipa capensis & 1.21 & $0.702 \pm 0.017$ & 12.05 \\
\hline Linum strictum & 1.16 & $0.620 \pm 0.013(36)$ & 9.34 \\
\hline Lavanduia multifida & 1.01 & $0.655 \pm 0.017(38)$ & 9.04 \\
\hline Dactylis glomerata & 0.97 & $0.639 \pm 0.013(37)$ & 11.03 \\
\hline Helianthemum almeriense & 0.92 & $0.699 \pm 0.018$ & 11.02 \\
\hline Ulex parviflorus & 0.92 & $0.749 \pm 0.016$ & 15.40 \\
\hline Genista spartioides & 0.85 & $0.801 \pm 0.020(24)$ & 14.96 \\
\hline Fumana laevipes & 0.85 & $0.642 \pm 0.012(26)$ & 11.42 \\
\hline Genista ramosissima & 0.75 & $0.751 \pm 0.014$ & 17.30 \\
\hline Cardutus tenuiflorus & 0.71 & $0.662 \pm 0.013(20)$ & 12.18 \\
\hline Teucrium charidemi & 0.70 & $0.617 \pm 0.009(30)$ & 12.99 \\
\hline Avenula gervaisii & 0.64 & $0.716 \pm 0.045(6)$ & 4.75 \\
\hline Ballota hirsuta & 0.64 & $0.668 \pm 0.015(29)$ & 11.20 \\
\hline Bromus rubens & 0.64 & $0.692 \pm 0.016(23)$ & 11.85 \\
\hline Silene colorata & 0.61 & $0.614 \pm 0.013$ & 8.48 \\
\hline Asteriscus maritimus & 0.60 & $0.681 \pm 0.014(15)$ & 13.24 \\
\hline Stoibrax dichotomum & 0.59 & $0.654 \pm 0.021(13)$ & 7.52 \\
\hline Teucrium pseudo-chamaepitys & 0.59 & $0.641 \pm 0.014(17)$ & 9.81 \\
\hline Leontodon ionginrostris & 0.58 & $0.603 \pm 0.012(32)$ & 8.23 \\
\hline Salsola genistoides & 0.57 & $0.719 \pm 0.016(33)$ & 13.75 \\
\hline Fagonia cretica & 0.57 & $0.619 \pm 0.018(28)$ & 6.63 \\
\hline Cistus albidus & 0.56 & $0.718 \pm 0.030$ & 7.30 \\
\hline Avena barbara & 0.53 & $0.647 \pm 0.020$ & 7.29 \\
\hline Phagnalon saxatile & 0.32 & $0.621 \pm 0.022(22)$ & 5.53 \\
\hline Olea europaea & 0.10 & $0.834 \pm 0.043(10)$ & 7.77 \\
\hline
\end{tabular}


Table 3 - Linear regressions between the DFA exponent and frequency, and patch size (log transformed) and patch distance, for the most abundant plant species in the dwarf matorral of Cabo de Gata Natural Park, SE Spain.

\begin{tabular}{|c|c|c|c|c|c|c|c|c|}
\hline \multirow[t]{3}{*}{ Specjes } & \multicolumn{4}{|c|}{ Patch size } & \multicolumn{4}{|c|}{ Patch distance } \\
\hline & \multicolumn{2}{|c|}{ DFA } & \multicolumn{2}{|c|}{ Frequency } & \multicolumn{2}{|c|}{ DFA } & \multicolumn{2}{|c|}{ Frequency } \\
\hline & Slope & $F$ & Slope & $\mathbf{F}_{1,51}$ & Slope & $F$ & Slope & $F_{1,51}$ \\
\hline \multicolumn{9}{|l|}{ Shrubs } \\
\hline Chamaerops humilis & 0.013 & $11.25^{*+}$ & 28.77 & $17.44^{+\cdots \bullet}$ & -0.000 & 1.30 & -3.21 & $8.09^{\prime \prime}$ \\
\hline Thymus hyemalis & 0.010 & $8.01^{\circ}$ & 13.54 & $4.40^{\circ}$ & -0.000 & 1.06 & -3.07 & $10.89^{\prime \prime}$ \\
\hline Periploca laevigata & 0.018 & $13.19^{* * *}$ & 5.13 & 1.25 & 0.000 & 0.01 & -0.45 & 0.41 \\
\hline Phiomis purpurea & 0.010 & $5.36^{\circ}$ & 3.63 & 1.89 & 0.000 & 0.00 & -1.03 & $7.18^{*}$ \\
\hline Anthyllis cytisoides & 0.025 & $9.49^{*+}$ & 0.46 & 0.01 & -0.003 & $7.24^{+}$ & -0.90 & 0.88 \\
\hline Lavanduia muitifida & -0.005 & 0.04 & 6.56 & $18.23^{\prime \prime \prime}$ & 0.000 & 0.46 & -0.16 & 0.35 \\
\hline Helianthemum almeriense & 0.015 & $5.00^{\circ}$ & -2.72 & 1.59 & 0.000 & 0.01 & -0.31 & 0.90 \\
\hline Ulex parviflorus & 0.005 & 0.42 & 3.16 & 0.94 & 0.000 & 0.36 & -1.20 & $6.48^{\circ}$ \\
\hline Genista spartioides & 0.021 & $7.13^{*}$ & 2.94 & 2.08 & 0.000 & 0.01 & 0.41 & 1.78 \\
\hline Fumana iaevipes & 0.003 & 0.33 & -1.56 & 1.18 & -0.001 & 2.92 & -0.68 & $11.58^{\prime \prime}$ \\
\hline Genista ramosissima & 0.005 & 0.36 & 1.36 & 2.15 & 0.000 & 0.44 & 0.16 & 1.26 \\
\hline Teucrium charidemi & 0.001 & 0.03 & 2.92 & $5.99^{\circ}$ & -0.001 & 1.48 & -0.35 & 3.61 \\
\hline Ballota hirsuta & 0.016 & $4.97^{\circ}$ & 3.45 & $5.54^{\circ}$ & -0.001 & 1.38 & -0.51 & $5.11^{\circ}$ \\
\hline Asteriscus maritimus & -0.002 & 0.04 & -0.74 & 0.18 & -0.001 & 2.43 & 0.75 & $9.56^{\prime \prime}$ \\
\hline Stoibrax dichotomum & -0.020 & 1.05 & 1.22 & 0.66 & -0.001 & 0.26 & -0.66 & $10.00^{\prime \prime}$ \\
\hline Teucrium pseudo-chamaepitys & 0.018 & $9.44^{*}$ & 0.23 & 0.20 & -0.002 & $4.92^{\circ}$ & -0.16 & $4.33^{\circ}$ \\
\hline Salsola genistoides & 0.010 & 1.43 & 3.01 & $13.12^{\cdots}$ & -0.003 & $8.94^{* *}$ & 0.23 & 2.73 \\
\hline Fagonia cretica & -0.020 & $4.52^{+}$ & -0.41 & 0.26 & 0.000 & 0.01 & -0.18 & 2.26 \\
\hline Cistus albidus & 0.036 & $7.45^{\circ}$ & 0.26 & 0.03 & -0.004 & $7.40^{\circ}$ & -0.55 & $5.36^{\circ}$ \\
\hline Phagnalon saxatile & -0.027 & $13.72^{\cdots *}$ & 0.28 & 0.65 & 0.002 & 2.13 & -0.16 & $10.85^{*}$ \\
\hline Olea europaea & -0.047 & 2.48 & -0.27 & 0.59 & 0.002 & 0.28 & -0.07 & 2.08 \\
\hline \multicolumn{9}{|l|}{ Forbs } \\
\hline Plantago amplexicaulis & -0.002 & 0.24 & 0.73 & 0.05 & 0.001 & 3.04 & 0.15 & 0.09 \\
\hline Launaea lanifera & 0.004 & 1.03 & 0.81 & 0.25 & 0.001 & 2.31 & 0.05 & 0.05 \\
\hline Asparagus horridus & 0.007 & 1.58 & 4.43 & $20.07^{\prime \prime \prime}$ & 0.000 & 0.00 & 0.00 & 0.53 \\
\hline Limum strictum & 0.013 & $5.37^{+}$ & -2.42 & 1.37 & 0.000 & 0.00 & -0.51 & 2.68 \\
\hline Carduus tenuifforus & 0.015 & 2.12 & 1.65 & 0.88 & -0.000 & 0.07 & -0.63 & $6.17^{\circ}$ \\
\hline Silene colorata & -0.000 & 0.01 & 1.63 & 0.46 & -0.000 & 0.29 & -0.08 & 0.05 \\
\hline Leontodon longirrostris & 0.010 & 2.94 & 1.02 & 1.24 & -0.001 & 2.93 & -0.44 & $11.59^{\prime \prime}$ \\
\hline \multicolumn{9}{|l|}{ Grasses } \\
\hline Stipa tenacissima & 0.006 & 1.72 & -23.65 & 1.16 & -0.00 & 1.04 & -1.49 & 0.19 \\
\hline Brachypodium retusum & 0.023 & $12.81^{++*}$ & 24.05 & $8.74^{\prime \prime}$ & -0.00 & 0.03 & -2.31 & 3.15 \\
\hline Brachypodium distachyon & -0.004 & 0.26 & 0.61 & 0.01 & 0.00 & 0.14 & 0.21 & 0.06 \\
\hline Stipa capensis & -0.005 & 0.43 & 2.32 & 0.98 & 0.00 & 0.37 & -0.40 & 1.24 \\
\hline Dactylis glomerata & -0.001 & 0.01 & 1.88 & 1.43 & 0.00 & 1.40 & -0.02 & 0.00 \\
\hline Avenula gervaisii & 0.054 & 1.80 & 0.01 & 0.00 & -0.002 & 0.08 & -0.10 & 1.32 \\
\hline Bromus rubens & 0.021 & $8.91^{* *}$ & 3.11 & $4.86^{\circ}$ & 0.00 & 0.00 & 0.26 & 1.36 \\
\hline Avena barbara & 0.018 & 1.58 & 2.28 & 2.87 & -0.001 & 1.15 & -0.54 & $7.60^{\circ}$ \\
\hline $\begin{array}{l}P<0.05 \\
P<0.01 \\
P<0.001\end{array}$ & & & & & & & & \\
\hline
\end{tabular}

size in the absence of a change in the degree of long-range spatial autocorrelation (Table 3).

Inter-patch distance had a significant negative effect on the frequency of the most abundant shrubs; consequently, species richness and inter-patch distance were significantly negatively correlated $\left(R^{2}=0.09, F_{1,51}=5.11, P=0.02\right)$. Meanwhile, the influence of inter-patch distance on the disruption of spatial organized patterns was only significant for $C$. albidus, $T$. pseudochamaepitys, A. cytisoides, and S. genistoides. Inter-patch distance had a significant disruptive effect on the long-range spatial autocorrelation of C. albidus, T. pseudochamaepitys, A. cytisoides, and S. genistoides, only.

Species spatial distribution (estimated by $D_{I}$ ) and patch size were negatively correlated $\left(R^{2}=0.09\right.$, slope $=-0.001$,
$\left.F_{1,51}=5.30, P<0.05\right)$. That is, the smaller the size of the patch, the more homogeneous was the species spatial distribution. $D_{I}$ and inter-patch distance were not significantly correlated $\left(F_{1,51}=1.65\right)$.

\section{Discussion}

In Cabo de Gata Natural Park, southeastem Spain, the spatial discontinuity of vegetation patches limited species distributions. Among-patch diversity $\left(\beta_{2}\right)$ was higher and amongtransect diversity $\left(\beta_{1}\right)$ was lower than expected based on random simulations. Those phenomena occur within such diverse communities as serpentine plants (Freestone and 

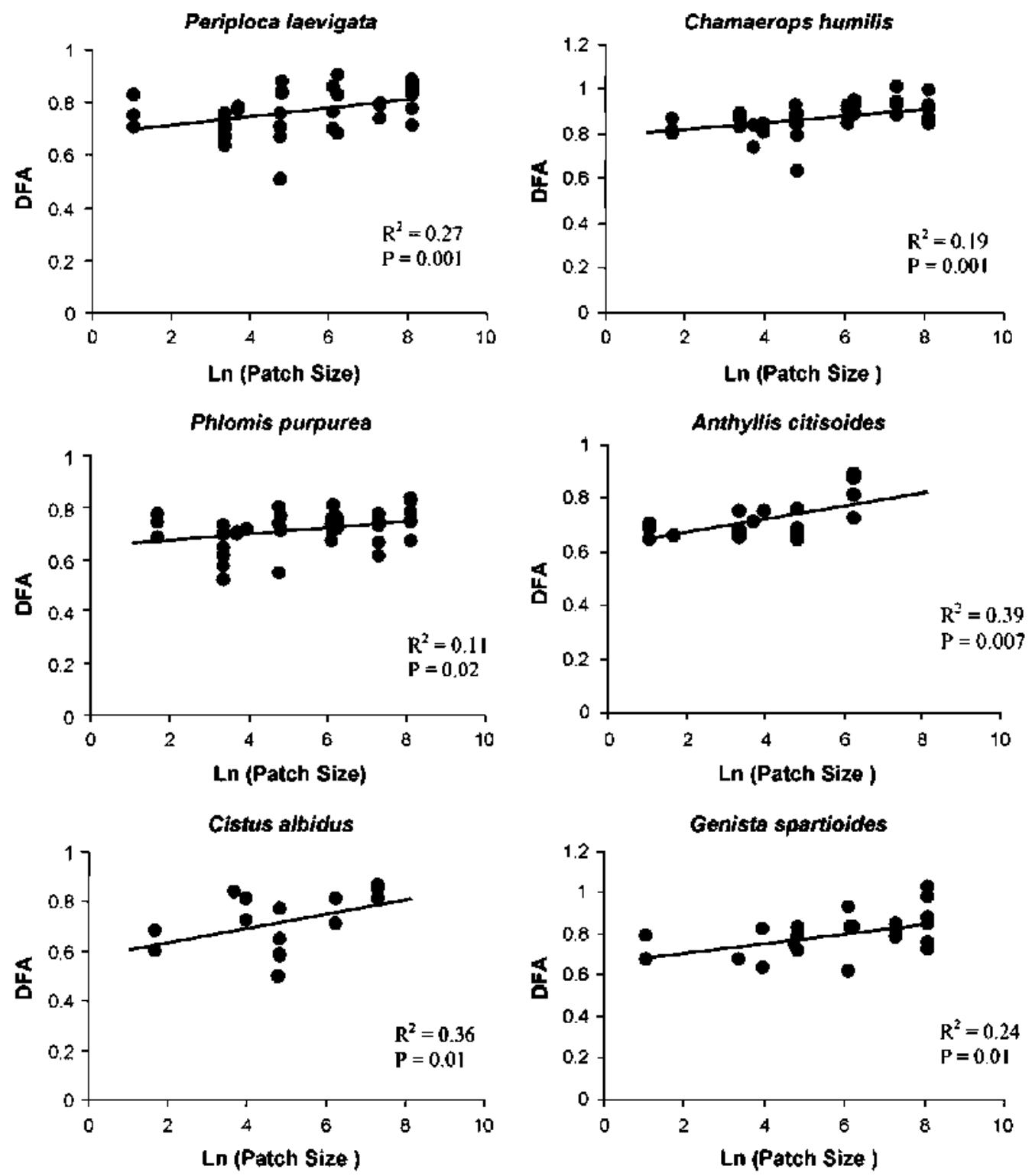

Fig. 3 - Exponents of the Detrended Fluctuation Analysis (DFA) and the natural logarithm of patch size (km) among plant species that exhibited a significant disruption in spatial autocorrelation as the extent of habitat fragmentation increased in the dwarf matorral community of Cabo de Gata Natural Park, SE Spain.

Inouye, 2006) and beetles (Crist et al., 2003; Gering et a]., 2003) Apparently, landscape configuration affects the spatial distribution of plant diversity, with differentiation in species composition between patches and homogenization of composition within patches.

High beta diversity among patches can increase the overall species diversity of the landscape, which has lead to a debate over whether many small fragments are better than a few large fragments within a reserve network (Quinn and Harrison, 1988; Gabriel et al., 2006). The two main mechanisms underlying the relationship between species richness and habitat area (Rosenzweig, 1995) are the "rescue effect," i.e., an increase in the probability of the recolonization of an empty space (Brown and Kodric-Brown, 1977; Xu et al, 2006), and the "habitat heterogeneity effect," i.e., a wider range of environ- mental conditions in large areas (Honnay et al., 1999; Brose, 2001). To better understand those mechanisms, the ways in which patch size and isolation influence species spatial distributions need to be understood.

As expected if passive diffusion is a homogenizing process, in the matorral community of Cabo de Gata N.P. amongtransect variability was lower in large patches than it was in small patches. Similar results are expected if diffusion occurs over a long period, e.g., in long-lasting, well-established patches (Kareiva, 1982). The beta diversity of aquatic invertebrates was higher in fragmented habitats than it was in continuous floodplain channels (Tockner et al., 1999).

Communities consist of populations of taxa that interact with each other in a nonlinear way and with the environment, and are connected by dispersal to a network that constitutes a 

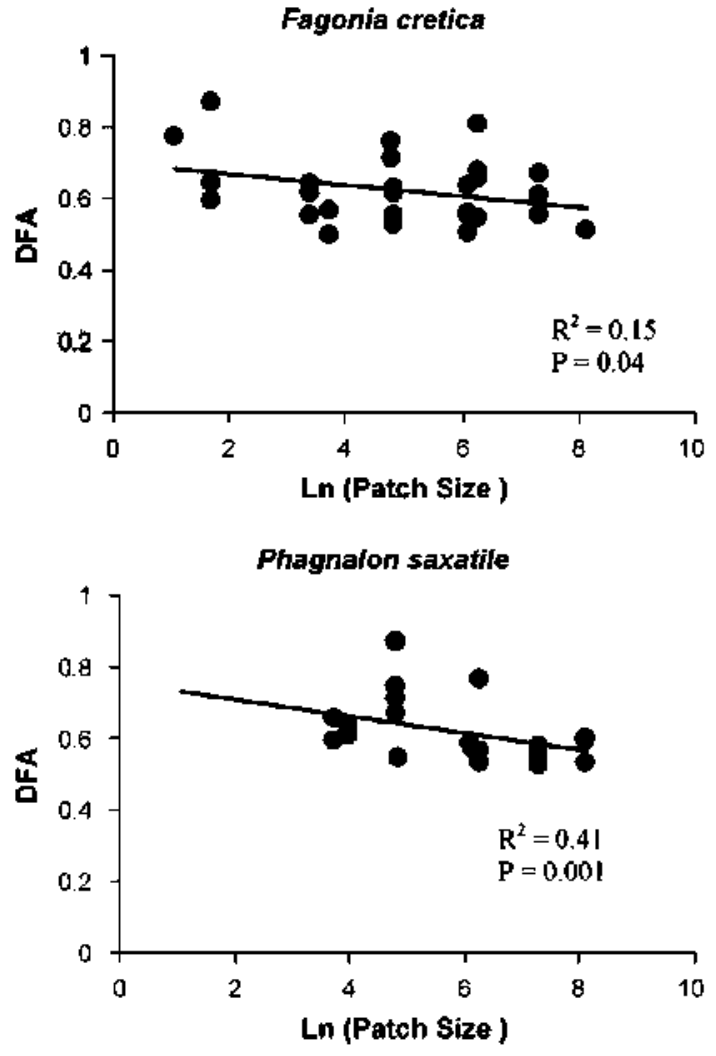

Fig. 4 - Exponents of the Detrended Fluctuation Analysis (DFA) and the natural logarithm of patch size (km) among plant species that exhibited an increase in spatial autocorrelation as the extent of habitat fragmentation increased in the dwarf matorral community of Cabo de Gata Natural Park, SE Spain.

metacommunity (Leibold et al., 2004). In the early stages of colonization, plants colonize space in a random manner until strong interactions arise among species (Kershaw, 1963; Fowler, 1990). Over time and space, opportunities for interactions among individuals arise and structural patterns develop, which gives rise to an increase in vegetation heterogeneity throughout vegetation succession (Loehle et al., 1996; Cook et al., 2005). In our study, as patch size increased, the degree of long-range spatial autocorrelation of the characteristic species that constitute the community increased; i.e., small patch size and, to a lesser extent, an increase in inter-patch distance disrupted the spatial organized pattern of the dominant shrubs species. Furthermore, heterogeneity was higher (the $\mathrm{D}_{\mathrm{I}}$ was lower) in large patches than it was in small patches, where there are more opportunities for plant interactions and the development of self-organized spatial patterns.

Long-term, self-organizing biological processes (mutualistic interactions) can arise from interactions among individuals, which generate an area of influence that affects the surrounding space (Wu et al., 1985; Grau, 2002). Spatial patterns can facilitate the coexistence of species by concentrating resources around the plant canopy and generating small-scale spatial associations among species (Choler et al.,
2001); however, those processes can vary depending on the life-history traits of the species (Kolb and Diekmann, 2005; Adriaens et al, 2006). Therefore, an understanding of species' life-histories can help in determining which species are most susceptible to ecosystem fragmentation. In Cabo de Gata Natural Park, forest-gap species that have restricted dispersal, e.g. Phlomis purpurea, Cistus albidus, Teucrium pseudochamaepytis, Genista spartioides, and Brachypodium retusum (the only grass species, along with Bromus rubens, sensitive to patch size, and species that actively restrict and hamper dispersal (antitelechory) by myxospermy, which are predominant in arid regions (Ehrman and Cocks, 1996), e.g., Helianthemum almeriensis (Melendo et al., 2003) and Linum strictum (Hensen, 1999), are very sensitive to the effects of fragmentation and exhibited a significant positive correlation between patch size and the long-range spatial autocorrelation. Those species recolonize more slowly than do wind-dispersed species, e.g., the flying, anemochorous Launaea ianifera, which tend to dominate the early stages of succession (Dzwonko and Loster, 1992), and vertebrate dispersers, e.g., Olea europaea var. sylvestris (Bratton et al., 1994; Drayton and Primack, 1996). In addition, even though they are found in early successional habitats that are often dominated by wind-dispersed species (Salisbury, 1942; Dzwonko, 1993; Navarro et al., 2006), Thymus hyemalis, Anthylis cytisoides and Ballota hirsuta are strongly allogamous. Indeed, $A$. cytisoides is a leguminous species that is connected underground by the Rhizobium nodules that form closed populations that are self-enforced through positive feedback. Finally, the remnants of native, late-successional sprouting shrubs, e.g., Periploca laevigata and Chamaerops humilis, are species that have a large canopy, which facilitates persistence and establishment, and enhances ecosystem functioning (Maestre and Cortina, 2004). Although those species are resilient against disturbances (Trabaud,1991), they are sensitive to the effect of isolation.

In Cabo de Gata N.P., a few species increased their longrange correlation with a decrease in patch size. Those species are typical of highly degraded, anid ecosystems and, in a fragmented landscape, might have advantages over species that are characteristic of more pristine habitats. Those species are Fagonia cretica and Phagnalon saxatile. In addition, F. cretica is a xeric prostrate herb that hampers dispersal through basicarpy, which enables survival in arid ecosystems (Van Rheede van Outshoom and Van Rooyen, 1999) and facilitates resistance to the effects of isolation. Those species are able to persist in fragmented landscapes until the degree of fragmentation exceeds a threshold, when decreased connectivity limits the "rescue effect" (Lande, 1988; Kareiva and Wennergren, 1995; Ovaskainen et al., 2002; Xu et al., 2006).

Species' life-history traits influence their responses to fragmentation (Kolb and Diekmann, 2005; Adriaens et al., 2006). Species that have traits that favor colonization by, for example, wind dispersal (Hovestadt et al., 1999) and windpollination (Hobbs and Yates, 2003) are less susceptible to the effects of isolation, and can even increase overall species richness (Fahrig, 2003; Harper et al, 2005). In fragmented landscapes, species that have intrinsically low population growth rates and short-range dispersal are vulnerable to extinction (Johst et al., 2002; Verheyen et al., 2004), e.g., in a dynamic landscape, slow-colonizing species have much lower 
patch occupancy than do rapid colonizers (Eriksson and Ehrlén, 1992; Ehrlen and Eriksson, 2000; Dupré and Ehrlén, 2002). In addition, disturbed plant-pollinator interactions can lead to reduced fecundity in fragmented landscapes Uennersten, 1988).

In our study, we showed that species characteristic of the matorral community disrupt long-range spatial autocorrelation in response to fragmentation. Quantification of the degree of long-range spatial autocorrelation can be used to indicate the risk of loss of biodiversity in fragmented landscapes before a reduction in plant diversity can be detected and a cascade of extinctions occurs.

In summary, in the fragmented landscape of Cabo de Gata N.P., southeastern Spain, variation in species diversity acted at two scales. Between patches, spatial variation in species distributions was greater than that expected based on spatial randomization. Within patches, diffusion processes reduced spatial variability in species distributions, and the effect was most prominent in large patches. In addition, the long-range spatial autocorrelation that result from plant interactions and limitations on dispersal increased the heterogeneity of the spatial distributions of species.

We conclude that changes in the long-range spatial autocorrelation of plant species in response to differences in patch size indicate that spatial organizing processes are important factors in the conservation of large and wellconnected patches, and that the most effective way to protect against the effects of fragmentation in semi-arid ecosystems is to protect restricted-dispersal species and to reinforce selforganizing processes as positive feedback interactions which will allow self-structuring mechanisms to operate.

\section{Acknowledgements}

We gratefully acknowledge the support of the Spanish CICYT (CGL2005-01625/BOS). We thank Beatriz Bueno and Elena Lahoz for assisting in the collection of field data. We thank Bruce MacWhirter for critically reading and providing helpful suggestions on the manuscript.

\section{REFERENCES}

Aarssen, L.W., Turkington, R., 1985. Vegetation dynamics and neighbour associations in pasture-community evolution. J. Ecol. 73, 585-603.

Adriaens, D., Honnay, O., Hermy, M., 2006. No evidence of a plant extinction debt in highly fragmented calcareous grasslands in Belgium. Biol. Conserv. 133, 212-224.

Alados, C.L., Weber, D.N., 1999. Lead effects on the predictability of reproductive behavior in fathead minnows (Pimephales promelas): a mathematical model. Environ. Toxicol. Chem. $18,2392-2399$.

Alados, C.L., Pueyo, Y., Giner, M.L., Navarro, T., Escos, J., Barroso, F., Cabezudo, B., Emlen, J.M., 2003. Quantitative characterization of the regressive ecological succession by fractal analysis of plant spatial patterns. Ecol. Model. 163, 1-17.

Alados, C.L., Pueyo, Y., Barrantes, O., Escós, J., Giner, L., Robles, A.B., 2004. Variations in landscape patterns and vegetation cover between 1957 and 1994 in a semiarid Mediterranean ecosystem. Landscape Ecol. 19, 543-559.

Alados, C.L., Pueyo, Y., Navas, D., Cabezudo, B., González, A., Freeman, D.C., 2005. Fractal analysis of plant spatial patterns: a monitoring tool for vegetation transition shifts. Biodivers. Conserv. 14, 1453-1468.

Allan, J.D., 1975. Components of diversity. Oecologia 18, 359-367.

Ashkenazy, Y., Ivanova, P.C., Havlin, S., Peng, C.-K., Goldberger, A.L., Stanley, H.E., 2001. Magnitude and sign correlations in heartbeat fluctuations. Phys. Rev. Lett. 86, 1900-1903.

Barbier, N., Couteron, P., Lejoly, J., Deblauwe, V., Lejeune, O., 2006. Self-organized vegetation patterning as a fingerprint of climate and human impact on semi-arid ecosystems. ). Ecol. 94, 537-547.

Bertness, M.D., Callaway, R.M., 1994. Positive interactions in communities. Trends Ecol. Evol. 9, 191-193.

Bolker, B.M., Pacala, S.W., 1999. Spatial moment equations for plant competition: understanding spatial strategies and the advantages of short dispersal. Am. Nat. 162, 135-148.

Bratton, S.P., Hapeman, J.R., Mast, A.R., 1994. The lower Susquehanna River gorge and flood plain (USA) as a riparian refuge for vernal, forest-floor herbs. Conserv. Biol. 8, 10691077.

Brose, U., 2001. Relative importance of isolation, area and habitat heterogeneity for vascular plant species richness of temporary wetlands in east-German farmland. Ecography $24,722-730$.

Brown, J.H., Kodric-Brown, A., 1977. Turnover rates in insular biogeography: effects of immigration on extinction. Ecology $58,445-449$.

Buldyrev, S.V., Goldberger, A.L., Havlin, S., Mantegna, R.N., Matsa, M., Peng, C.-K., Simons, S., Stanley, H.E., 1995. Longrange correlations properties of coding and noncoding DNA sequences: GenBank analysis. Phys. Rev. E 51, 5084-5091.

Chen, X., Li, B.-L., Collins, S.L., 2005. Multiscale monitoring of a multispecies case study. two grass species at Sevilleta. Plant Ecol. 179, 149-154.

Chesson, P.L., Huntly, N., 2000. Mechanisms of maintenance of species diversity. Ann. Rev. Ecol. Syst. 31, 343-366.

Choler, P., Michalet, R., Callaway, R.M., 2001. Facilitation and competition on gradients in Alpine plant communities. Ecology 82, 3295-3308.

Cook, W.M., Yao, J., Foster, B.L., Holt, R.D., Patrick, B.L., 2005 Secondary succession in an experimentally fragmented landscape: community patterns across space and time. Ecology 86, 1267-1279.

Crist, T.O., Veech, J.A., Gering, J.C., Summerville, K.S., 2003. Partitioning species diversity across landscapes and regions: a hierarchical analysis of $\alpha, \beta, \gamma$ diversity. Am. Nat. $162,734-743$

Davies, K.F., Chesson, P., Harrison, S., Inouye, B.D., Melbourne, B.A., Rice, K.J., 2005. Spatial heterogeneity explains the scale dependence of the native-exotic diversity relationship. Ecology 86, 1602-1610.

Drayton, B., Primack, R.B., 1996. Plant species lost in an isolated conservation area in Metropolitan Boston from 1894 to 1993. Conserv. Biol. 11, 30-39.

Dupré, C., Ehrlén, J., 2002. Habitat configuration, species traits and plant distributions. J. Ecol. 90, 796-805.

Dzwonko, Z., Loster, S., 1992. Species richness and seed dispersal to secondary woods in southern Poland. J. Biogeogr. 19, 195-204.

Dzwonko, Z., 1993. Relations between the floristic composition of isolated young woods and their proximity to ancient woodland. \}, Veg. Sci, 4, 693-698.

Ehrlen, J., Eriksson, O., 2000. Dispersal limitation and patch occupancy in forest herbs. Ecology 81, 1667-1674. 
Ehrman, T., Cocks, P.S., 1996. Reproductive patterns in annual legume species on an aridity gradient. Plant Ecol. 122, 47-59.

Eriksson, O., Ehrlén, J., 1992. Seed and microsite limitation of recruitment in plant populations. Decologia 91,360-364.

Fahrig, L., 2003. Effects of habitat fragmentation on biodiversity. Ann. Rev. Ecol. Syst. 34, 487-515.

Farmer, D., Ott, E., Yorke, J.A., 1983. The dimension of chaotic attractors. Physica 7D, 153-180.

Fisher, M., Stöcklin, J., 1997. Local extinctions of plants in remnants of extensively used calcareous grasslands 19501985. Conserv. Biol. 11, 727-737.

Fowler, N.L., 1990. Disorderliness in plant communities: comparisons, causes and consequences. In: Grace, J.B. Tilman, D. (Eds.), Perspectives on Plant Competition. Academic Press Inc., San Diego, USA, pp. 291-306.

Freestone, A.L., Inouye, B.D., 2006. Dispersal limitation and environmental heterogeneity shape scale-dependent diversity patterns in plant communities. Ecology 87, 24252432.

Frelich, L.E., Reich, P.B., Sugita, S., Davis, M.B., Friedman, S.K., 1998. Neighbourhood effects in forests: implications for within stand patch structure and management. J. Ecol. 86 , 149-162.

Gabriel, D., Roschewitz, I, Tschamtke, T., Thies, C., 2006. Beta diversity at different spatial scales: plant communities in organic and conventional agriculture. Ecol. Appl. 16, 20112021.

Gering, J.C., Crist, T.O., Veech, J.A., 2003. Additive partitioning of species diversity across multiple spatial scales: Implications for regional conservation of biodiversity. Conserv. Biol. 17, 488-499.

Gil Albarracín, A., 2002. Viaje a Andalucía: Historia natural del reino de Granada (1804-1809). Griselda Bonet Girabet, Barcelona, 1247 pp.

Goodall, D.W., 1952. Some considerations in the use of point quadrats for the analysis of vegetation. Aust. J. Sci. Res. Bull. $5,1-41$.

Grau, H.R., 2002. Scale-dependent relationships between treefalls and species richness in a neotropical montana forest. Ecology 83, 2591-2601.

Green, D.G., Sadedin, S., 2005. Interactions matter-complexity in landscapes and ecosystems. Ecol. Complex. 2, 117-130.

Grime, J.P., 1998. Benefits of plant diversity to ecosystems: immediate, filter and founder effects. J. Ecol. 86, 902-910.

Halley, J.M., Hartley, S., Kallimanis, A.S., Kunin, W.E., Lennon, J.J., Sgardelis, S.P., 2004. Uses and abuses of fractal methodology in ecology. Ecol. Lett. 7, 254-271.

Hanski, 1, 1999. Metapopulation Ecology. Oxford University Press, New York, USA, $313 \mathrm{pp}$

Harper, K.A., Macdonald, E., Burton, P.J., Chen, J., Brosofske, K.D., Saunder, S.C., Euskirchen, E.S., Roberts, D., Jaiteh, M.S., Esseen, P., 2005. Edge influence on forest structure and composition in fragmented landscapes. Conserv. Biol. 19 , 768-782.

Hausdorff, J.M., Mitchell, S.L., Firtion, R., Peng, C.K., Cudkowicz, M.E., Wei, J.Y., Goldberger, A.L., 1997. Altered fractal dynamics of gait: reduced stride-interval correlations with aging and huntingtons disease. J. Appl. Physiol. 82, 262-269.

Hensen, I., 1999. Life strategies of semi-desert plants: mechanisms of dispersal and reproduction in the thermomediterranean shrubland community AnabasioEuzomodendretum bourgaeani. Anal. Jardín Botán. Madrid $57,63-79$.

HilleRisLambers, R., Rietkerk, M., van den Bosch, F., Prins, H.H.T., de Kroon, H., 2001. Vegetation pattem formation in semi-arid grazing systems. Ecology 82, 50-61.

Hobbs, R.J., Yates, C.J., 2003. Impacts of ecosystem fragmentation on plant populations: generalising the idiosyncratic. Aust. J. Bot. 51, 471-488.
Honnay, O., Endels, P., Vereecken, H., Hermy, M., 1999. The role of patch area and habitat diversity in explaining native plant species richness in disturbed suburban forest patches in northern Belgium. Divers. Distrib. 5, 129-141.

Hovestadt, T., Yao, P., Linsenmair, E.K., 1999. Seed dispersal mechanisms and the vegetation of forest islands in a West African forest-savanna mosaic (Comoé National Park, Ivory Coast). Plant Ecol. 144, 1-25.

Hu, K., lvanov, P.C., Chen, Z., Carpena, P., Stanley, H.E., 2001. Effect of trends on detrended fluctuation analysis. Phys. Rev. E 64, 1-19.

Ivanov, P.C., Goldberger, A.L., Stanley, H.E., 2002. Fractal and multifractal approaches in physiology. In: Bunde, A., Kropp, J., Schellnhuber, H.J. (Eds.), The Science of Disasters. Springer, Berlin, pp. 219-258.

Jennersten, O., 1988. Pollination in Dianthus deltoides (Caryophyllaceae): effects of habitat fragmentation on visitation and seed set. Conserv. Biol. 2, 359-366.

Jensen, H.J., 1998. Self-organized Criticality. Emergent Complex Behavior in Physical and Biological Systems. Cambridge University Press, $153 \mathrm{pp}$.

Johst, K., Brandl, R., Eber, S., 2002. Metapopulation persistence in dymamic landscapes: the role of dispersal distance. Oikos $98,263-270$

Kantelhardt, J.W., Koscielny-Bunde, E., Rego, H.H.A., Havlin, S., Bunde, A., 2001. Detecting long-range correlations with detrended fluctuation analysis. Physica A 295. $441-454$.

Kareiva, P., 1982. Experimental and mathematical analysis of herbivore movement: quantifying the influence of plant spacing and quality on foraging discrimination. Ecol. Monogr. 52, 261-282.

Kareiva, P., Wennergren, U., 1995. Connecting landscape pattems to ecosystem and population processes. Nature $373,299-302$.

Kershaw, K.A., 1963. Pattern in vegetation and its causality. Ecology 44, 377-388.

Klanderud, K., Totland, $\emptyset$., 2005. Simulated climate changes altered dominance hierarchies and diversity of an alpine biodiversity hotspot. Ecology 86, 2047-2054.

Kolb, A., Diekmann, M., 2005. Effects of life-history traits on responses of plant species to forest fragmentation. Conserv. Biol. 19, 929-938.

Lande, R., 1988. Genetics and demography in biological conservation. Science $241,1455-1460$.

Lande, R., 1996. Statistics and partitioning of species diversity, and similarity among multiple communities. Oikos 76, 5-13.

Lefever, R., Lejeune, O., 1997, On the origin of tiger bush. Bull. Math. Biol. 59, 263.

Leibold, M.A., Holyoak, M., Mouquet, N., Amarasekare, P., Chase, J.M., Hoopes, M.F., Holt, R.D., Shurin, J.B., Law, R., Tilman, D., Loreau, M., Gonzalez, A., 2004. The metacommunity concept: a framework for multi-scale community ecology. Ecol. Lett. 7, 601-613.

Lejeune, O., Tlidi, M., Couteron, P., 2002. Localized vegetation patches: a self-organized response to resource scarcity. Phys. Rev. E 66, 1-4.

Li, B.L., 2000. Fractal geometry applications in description and analysis of patch pattems and patch dynamics. Ecol. Model. $132,33-50$.

Livina, V.N., Lenton, T.M., 2007. A modified method for detecting incipient bifurcations in dynamical system. Geophys. Res. Lett. 34, 1-5.

Loehle, C., Li, B.L., Sundell, R.C., 1996. Forest spread and phase transitions at forest-prairie ecotones in Kansas, USA. Landscape Ecol. 11, 225-235.

Maestre, F.T., Cortina, J., 2004. Insights into ecosystem composition and function in a sequence of degraded semiarid steppes. Restor. Ecol. 12, 494-502. 
Manly, B.F.J., 2007. Randomization, Bootstrap and Monte Carlo Methods in Biology, 3rd ed. Chapman \& Hall/CRC, Boca Raton, $\mathrm{Fl}_{1} 455 \mathrm{p}$.

Melendo, M., Giménez, E., Cano, E., Gómez-Mercado, F., Valle, F., 2003. The endemic flora in the south of the Iberian Peninsula: taxonomic composition, biological spectrum, pollination, reproductive mode and dispersal. Flora 198, 260-276.

Miller, T.F., Mladenoff, D.)., Clayton, M.K., 2002. Old-growth northern hardwood forest: spatial autocorrelation and patterns of understory vegetation. Ecol. Monogr. 72, 487-503.

Moilanen, A., 2004. SPOMSIM: software for stochastic patch occupancy models of metapopulation dynamics. Ecol. Model. 179, 533-550.

Navarro, T., Alados, C.L., Cabezudo, B., 2006. Changes of plant functional types in response to grazing in two semiarid shrub-lands of SE coast Spain. J. Arid Environ. 64, 298-322.

Nicolis, G., 1989. Physics of far-from-equilibrium systems and self-organization. In: Davies, P. (Ed.), The New Physics. Cambridge University Press, Cambridge, pp. 316-330.

Ovaskainen, O., Sato, K., Bascompte, J., Hanski, I., 2002. Metapopulation models for extinction in spatially correlated landscapes. J. Theor. Biol. 215, 95-108.

Peinado, M., Alcaraz, F., Martínez-Parras, J.M., 1992. Vegetation of Southeastern Spain. J. Cramer, Berlin, 485 pp.

Peng, C.-K., Buldyrev, S.V., Goldberger, A.L., Havlin, S., Sciortino, F., Simons, M., Stanley, H.E., 1992. Long-range correlations in nucleotide sequences. Nature 356, 168-170.

Peng, C.-K., Buldyrev, S.V., Havlin, S., Simons, M., Stanley, H.E., Goldberger, A.L., 1994. Mosaic organization of DNA nucleotides. Phys. Rev. E 49, 1685-1689.

Pugnaire, F.I., Haase, P., Puigdefábregas, J., 1996. Facilitation between higher plant species in a semi-arid environment. Ecology 77, 1420-1426.

Quinn, J.F., Harrison, S.P., 1988. Effects of habitat fragmentation and isolation on species richness: evidence from biogeographic pattems. Oecologia 75, 132-140.

Rosenzweig, M.L., 1995. Species Diversity in Space and Time. Cambridge University Press, New York, USA, $436 \mathrm{pp}$.

Salisbury, E.F., 1942. The Reproductive Capacity of Plants, London, $244 \mathrm{pp}$

SAS Institute 2004. SAS/STAT User's guide. SAS Institute Inc. Cary N.C. USA

Schwarz, P.A., Fahey, T.J., McCulloch, C.E., 2003. Factors controlling spatial variation of tree species abundance in a forest landscape. Ecology 84, 1862-1878.

Seabloom, E.W., Bjørnstad, O.N., Bolker, B.M., Reichman, O.J., 2005. Spatial signature of environmental heterogeneity, dispersal, and competition in successional grasslands. Ecol. Monogr. 75, 199-214.

Solé, R.V., Alonso, D., Saldaña, J., 2004. Habitat fragmentation and biodiversity collapse in neutral communities. Ecol. Complex. 1, 65-75.
Solé, R.V., Bascompte, J., 2006. Self-organization in Complex Systems. Princeton University Press, $373 \mathrm{pp}$.

Soro, A., Sundberg, S., Rydin, H., 1999. Species diversity, niche metrics and species associations in harvested and undisturbed bogs. J. Veg. Sci. 10, 549-560.

Taqqu, M.S., Teverovsky, V., Willinger, M., 1995. Estimators for long range dependence: an empirical study. Fractal 3, 785798.

Telesca, L., Lasaponara, R., 2006. Vegetation patterns in burned and unburned areas investigated by using the detrended fluctuation analysis. Physica A 368, 531-535.

Telesca, L., Lasaponara, R., Lanorte, A., 2008. Intra-annual dynamical persistent mechanisms in mediterranean ecosystems revealed SPOT-vegetation time series. Ecol. Complex. 5, 151-156.

Thomas, J.A., Telfer, M.G., Roy, B.D., Preston, C.D., Greenwood, J.J.D., Asher, J., Braun-Blanquet, Fox, R., Clarke, R.T., Lawton, J.H., 2004. Comparative losses of British butterflies, birds and plants and the global extinction risk. Science 303, 18791881.

Tilman, D., 1994. Competition and biodiversity in spatially structured habitats. Ecology 75, 1-2.

Tockner, K., Schiemer, F., Baumgartner, C., Kum, G., Weigand, E., Zweimuller, I., Ward, J.V., 1999. The Danube restoration project: species diversity pattems across connectivity gradients in the floodplain system. Regul. Rivers Res. Manage. 15, 245-258.

Trabaud, L., 1991. Fire Regimes and phytomass growth dynamics in a Quercus coccifera garrigue. J. Veg. Sci. 2, 307314

Van Rheede van Outshoorn, K., Van Rooyen, M.W., 1999. Dispersal Biology of Desert Plants. Springer Verlag, New York, 242 pp.

Verheyen, K., Vellend, M., van Calster, H., Peterken, G., Hermy, $M ., 2004$. Metapopulation dynamics in a fragmented and dynamic landscape: forest plants in central Lincolnshire, United Kingdom. Ecology 85, 3302-3312.

Wagner, H.H., 2003. Spatial covariance in plants communities: integrating ordination, geostatistics, and variance testing. Ecology 84, 1045-1057.

Wagner, H.H., Wildi, O., Ewald, K.C., 2000. Additive partitioning of plant species diversity in an agricultural mosaic landscape. Landscape Ecol. 15, 219-227.

Whittaker, R.H., 1960. Vegetation of the Siskiyou Mountains, Oregon and California. Ecol. Monogr. 30, 279-338.

Whittaker, R.H., 1972. Evolution and measurement of species diversity. Taxon 21, 213-251.

Wright, C.K., 2008. Ecological community integration increases with added trophic complexity. Ecol. Complex. 5, 140-145.

Wu, H., Sharpe, P., Walker, J., Penridge, L., 1985. Ecological field theory: a spatial analysis of resource interference among plants. Ecol. Model. 29, 215-243.

Xu, D., Feng, Z., Allen, L.J.S., Swihart, K., 2006. A spatial structured metapopulation model with patch dynamics. J. Theor. Biol. 239, 469-481. 